\title{
ЕВРОПЕЙСКАЯ НАУКА: ПРОТИВОРЕЧИЯ И ПЕРСПЕКТИВЫ
}

Аннотация. Статья посвящена анализу противоречий в современной европейской и мировой науке. Автор утверждает, что современную науку характеризуют три типа противоречий: первый - между изменениями в исследовательском прочессе и типом управления ими, второй - между базовыми функциями современной науки, третий-между нарастающими потребностями социума в современных научных достижениях и кризисом доверия к науке в европейском массовом сознании. Последнее противоречие подробно рассматривается с использованием статистических данных Евробарометра. Установлено, что вымеупомянутые противоречия на сегодняшний день являются движущей силой развития как европейской, так и мировой науки.

Ключевые слова: наука, Европейский союз, общественное мнение, противоречия развития, перспективы.

Евробарометр регулярно проводит исследования общественного восприятия науки и инноваций. Исследования, проведённые в 2014 г., были посвящены анализу приоритетов общественного сознания на ближайшие 15 лет. Применительно к образовательному уровню респондентов было отмечено, что более половины европейцев (56\%) обладают научными знаниями. При этом 44\% опрошенных получили их в школе, а $16 \%$ - в университетах или колледжах.

Концепция исследования подразумевала двухуровневый опрос. На первом уровне респондентам предлагали список из нескольких социально значимых проблем, на основе которых опрашиваемые должны были выбрать самую, по их мнению, значимую. В списке присутствовали такие проблемы как: ${ }^{1}$

- создание рабочих мест;

- охрана здоровья и медицинская помощь;

- энергетика;

- образование и профессиональные навыки;

- борьба с изменением климата;

- питание.

В результате опроса в 16 странах Европейского союза на первом месте оказалось создание новых рабочих мест, а в 10 других странах первенство было отдано проблемам здоровья и медицинской помощи. Напротив, жители Швеции и Дании упомянули в качестве первоочередной задачи проблемы, касающиеся климатических изменений.

Одновре́менно не менее половины респондентов в Евросоюзе ожидают, что через 15 лет наука и технологии помогут развивать образование и профессиональную подготовку граж-

\footnotetext{
(с) Водопьянова Елена Викторовна - доктор философских наук, профессор, главный научный сотрудник Отдела социальных и политических исследований ИЕ РАН. Адрес: 125009, Россия, Москва, ул. Моховая, д. 11, стр. 3. E-mail: veritas-41@yandex.ru.
}

DOI: http://dx.doi.org/10.15211/vestnikieran22019151154

${ }^{1}$ Public perceptions of science, research and innovation. Special Eurobarometer 419. URL: http://ec.europa.eu/com mfrontoffice/publicopinion/archives/ebs/ebs_419_sum_en.pdf. 
дан (60\% опрошенных), транспорт и соответствующую инфраструктуру (59\%), энергоснабжение (58\%), защиту окружающей среды (57\%), а также качество жилья (50\%).

На втором уровне опроса предлагался выбор главного из предложенных научно-технологических приоритетов на ближайшие 15 лет. Отвечая на этот вопрос, жители 20 стран ЕС поставили на первое место охрану здоровья и медицину. Наибольшее число респондентов, ответивших таким образом (69\%), проживает в Испании. Однако только $43 \%$ опрошенных в Германии и лишь 44\% в Италии выбрали данный ответ. Можно предположить, что причины выбора такого ответа населением Германии коренятся в достаточно высоком, по их мнению, уровне национальной медицины, что позволяет обратить большее внимание на иные научнотехнологические приоритеты.

Выбор, сделанный жителями Италии, трудно объяснить столь однозначно. Во всех странах, за исключением Италии, 65\% участвовавших в опросе Евробарометра согласились с тезисом о том, что научно-технологические инновации в ближайшие 15 лет окажут влияние на здоровье и медицинскую помощь. Особую роль инноваций в этом процессе подчеркнули респонденты в Нидерландах (84\%), Швеции (83\%) и Дании (82\%), т.е. жители стран с давними традициями инженерных школ и с высокими национальными расходами на науку.

Большинство участников опроса Евробарометра отдали предпочтение науке и инновациям как базовому средству решения важнейших социальных проблем. Логично предположить, что такой выбор в значительной мере коренится в сохранившемся пиетете перед наукой 60-х гг. ХХ в. Однако сегодня эти предпочтения всё более подвергаются эрозии. Безусловно, за более чем 50 лет с момента её «сциентистского триумфа» наука изменилась как способ деятельности. В значительной мере наука стала ориентироваться на прибыль.

Не в последнюю очередь в этом повинна сама наука. Впрочем, те социокультурные координаты, в которых она сегодня вынуждена развиваться, также вносят немалый вклад в исследовательские реалии. Именно о них и пойдет рёчь.

Прошедшие два десятилетия XXI в. кардинально изменили как доминирующие технологии научного менеджмента и их осмысление, так и отношение европейской общественности к науке. Эти тенденции отражаются не только в статистике Евробарометра, но и в документах Евросоюза; они обозначают динамику взаимодействия наук с социумом несколькими формулами: «Наука $\underline{\underline{\varepsilon}}$ обществе», «Наука $\underline{c}$ обществом», «Наука $\underline{u}$ общество» ${ }^{1}$. Как можно заметить, последняя формулировка вновь делает попытку отразить в своём содержании утраченное доминирование исследовательской сферы над социумом.

При этом список прорывных научных направлений XXI в. за два прошедших десятилетия совершенно не изменился. Здесь Европа не стала исключением, а лишь воспроизвела общие, наметившиеся в мире тенденции. Однако изменились идеалы и нормы исследований в границах, казалось бы, неизменных научных дисциплин и направлений. Речь, прежде всего, идёт о сформировавшейся модели «постнормальной науки» (post-normal science, (PNS).

Предшествующий термин «нормальная наука» ведёт своё начало от укоренившейся позиции Томаса Куна, изложенной в работе 1962 г. «Структура научных революций». Данная наука полностью вписывалась в такие нормы как бескорыстность, доступность знаний и организованный скептицизм. Постнормальная наука диаметрально противоположна: она глубоко неопределённа, открыта, коммерциализирована, метапредметна, а также нацелена на управление устойчивым развитием².

${ }^{1}$ A.G. Pereira, A. Saltelli. Post-normal institutional identities: Quality assurance, reflexivity and ethos of care. Futures, V. 91. 2017. P. 57.

${ }^{2}$ Kønig N., Borsen T., Emmeche C. The ethos of post-normal science. Futures. V. 91. August, 2017. P. 12-24. URL: Научно-аналитический вестник ИЕ РАН, 2019, №2 
Постнормальная наука не исключает прежнюю нормальную науку. Она пытается, хотя и не всегда успешно, существовать с ней параллельно, учитывая, что «неправильное применение методик нормальной науки к сложным вопросам, имеющим отношение к политике, привело к множеству опасностей и растущему недоверию общественности» ${ }^{1}$. Нормальная наука по-прежнему довольно точно моделирует технологии прикладного знания с их достаточно высоким уровнем репродукции. А неким переходом к моделям постнормальной науки можно считать, в частности, профессиональное консультирование в медицине. Но в чистом виде лишь с помощью моделей PNS ныне становится возможным описать выходы исследовательского процесса в такие сферы с высоким уровнем неопределённости и низким уровнем доверия, как политика, журналистика, современное массовое сознание европейцев и т.п.

По результатам проведённого опроса жители североевропейских стран, а также Ирландии, Мальты и Испании отнеслись весьма оптимистично к сциентистским перспективам общества, основанного на знаниях. Напротив, согласно приведённым данным, менее оптимистичны жители Австрии, Германии, Греции, Чехии и Италии. Практически невозможно выявить в этих предпочтениях причинно-следственные связи, основываясь на детерминантах парадигмы классической «нормальной науки».

В эволюции европейской версии постнормальной науки работает модель широкого участия «снизу вверх», то есть от населения к учёным. Какие сферы в наибольшей степени ожидает такое участие? По-видимому, речь прежде всего пойдёт об исследованиях, касающихся экспертизы использования ГМО, анализа факторов, влияющих на климат, а также проблем безопасного захоронения ядерных отходов. В 2019 г. превалирует точка зрения, основанная на том, что вовсе не «граждане не понимают науку, а просто население не может разобраться, кому из экспертов доверять» ${ }^{2}$.

Европейская наука не утратила полностью своей «нормальной» сути, однако, взаимодействие диктуемых ею классических стратегий гуманизации человека и социума ныне реализуется всё более противоречиво в условиях:

- зависимости от логики и потребностей европейского рынка;

- диктата удешевления/экономизации исследований в Евросоюзе;

- трудностей менеджмента в науке, коренящихся в ограничениях, диктуемых коммерциализацией;

- кризиса безусловного доверия к науке, относящегося как к ожидаемым от неё результатам, так и к её этическим стандартам. На этом фоне всё чаще звучат предложения о том, чтобы европейские учёные принимали этическую присягу по аналогии с врачами ${ }^{3}$.

Одновре́менно на смену научной этике приходят объективные наукометрические показатели. Учёные, в свою очередь, обвиняют в иррациональности политиков и менеджеров.

Таким образом, современную науку характеризуют три типа противоречий:

- между изменениями в исследовательском процессе и типом управления ими;

- между базовыми (познавательной и инновационной) функциями современной науки;

- между нарастающими потребностями социума в современных научных достижениях и кризисом доверия к науке в европейском массовом сознании. В настоящий момент эти противоречия являются движущей силой развития как европейской, так и мировой науки в целом, а также её основных направлений: науки о жизни, информационных технологий, энер-

https://www.sciencedirect.com/science/article/pii/S0016328717300149?dgcid=raven_sd_recommender_email.

${ }^{1}$ Ibid.

${ }^{2}$ Kahan D.M. On the Sources of Ordinary Science Knowledge and Extraordinary Science Ignorance. Oxford handbook on the science of science communication. 2016.

${ }^{3}$ Whipple T. Scientists «should take ethics oath, like doctors». The Times. 22.02.2016. Научно-аналитический вестник ИЕ РАН, 2019, №2 
гетики и материаловедения. Согласно результатам опросов Евробарометра, именно на эти исследовательские приоритеты ориентированы жители европейских стран. Однако населению (как, впрочем, и самим учёным) в постиндустриальную эпоху ещёпредстоит пройти долгий и непростой путь к принятию стандартов гибкости и доверия по отношению к новой научной реальности.

\section{Список литературы / References}

Funtowicz S.O., Ravetz J.R. Science for the post-normal age. Futures, 25(7), 1993. P. 739-755.

Hess D. Alternative Pathways in Science and Industry, MIT Press, Cambridge, MA, USA, 2007.

Kahan D.M. On the Sources of Ordinary Science Knowledge and Extraordinary Science Ignorance. Oxford handbook on the science of science communication, 2016.

Kønig N., Borsen T., Emmeche C. The ethos of post-normal science. Futures. V. 91. August, 2017. P. 12-24. URL: https://www.sciencedirect.com/science/article/pii/S0016328717300149?dgcid =raven_sd_recommender_email.

Mirowski P. Science-mart: Privatizing American science. Harvard University Press, 2011.

Whipple T. Scientists «should take ethics oath, like doctors». The Times, 22.02.2016.

Public perceptions of science, research and innovation. Special Eurobarometer 419. URL: http://ec.europa.eu/commfrontoffice/publicopinion/archives/ebs/ebs_419_sum_en.pdf.

\section{European Science: Contradictions and Perspectives}

Author. Elena Vodopianova, Doctor of Sciences (Philosophy), Professor, Senior Research Associate, Institute of Europe, Russian Academy of Sciences. Address: 11-3, Mokhovaya str., Moscow, Russia, 125009. E-mail: veritas-41@ yandex.ru.

Abstract. This paper examines the contradictions in the modern European/world science. The author argues that the modern science is characterized by three types of contradictions. The first type is the change of the research process and the type of management, the second one is basic function of modern science, and the third one is the growing need of society in modern scientific achievements and the crisis of trust in science in the European mass consciousness. The last contradiction is analyzed in detail with the use of statistical data of Eurobarometer. It is stated that the above-mentioned contradictions are the driving force for the development of both European and world science.

Key words: science, European Union, public opinion, development contradictions, prospects.

DOI: http://dx.doi.org/10.15211/vestnikieran22019151154 